\title{
THE CLINICAL IMPORTANCE OF OUTPATIENT CLINIC IN THE REHABILITATION OF PATIENTS WITH MAJOR DEPRESSIVE DISORDER
}

\section{R. Correia ${ }^{1}$}

1- Centro Hospitalar Universitário do Algarve, Departamento de Psiquiatria e Saúde Mental, Faro, Portugal. saraivacorreia@gmail.com

\section{OBJECTIVES:}

To compare the clinical evolution of inpatients with Major Depressive Disorder (MDD) after discharge attending an Psychiatric Outpatient Clinic with inpatients with MDD after discharge not attending an outpatient clinic.

\section{BACKGROUND:}

The Psychiatric Outpatient Clinic attendance is often advocated as a tool for rehabilitation of patients with MDD who need daily mental health care in their treatment process. The Psychiatric OC provides an individualized treatment plan for clinical and rehabilitation purposes. There has been a renewed interest in Psychiatric OC in recent years due to the evidence supporting the costeffectiveness of these units, as well as the existing social advantages and decreased readmissions among other clinical and social benefits.
METHODOLOGY:

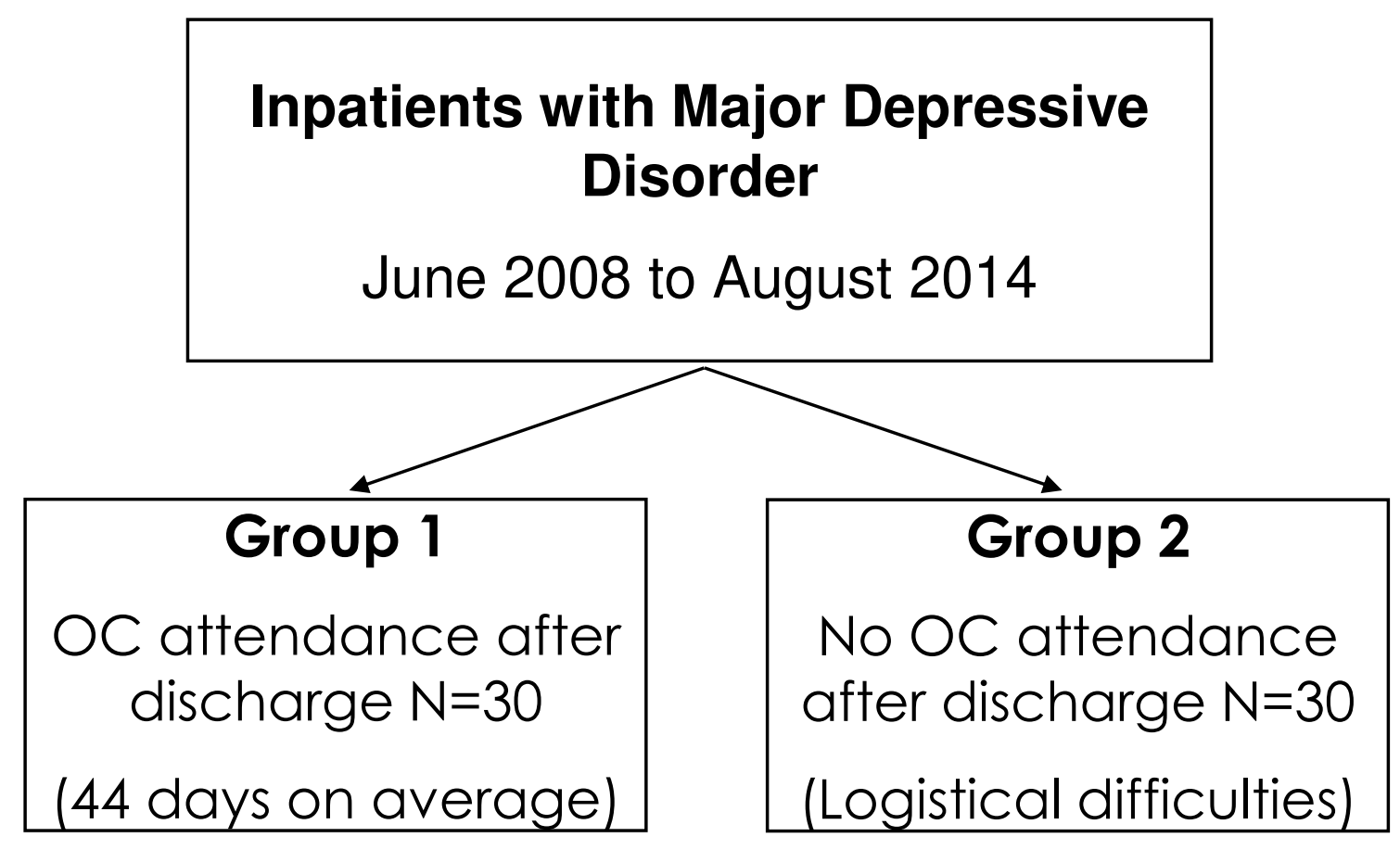

Follow-up after 3 years

ASSESSMENT:

-Number of psychiatric readmissions

-Readmissions Duration

-Number of psychiatric ER episodes

- Number of suicide attempts

-Rehabilitation evaluation

-Professional reintegration

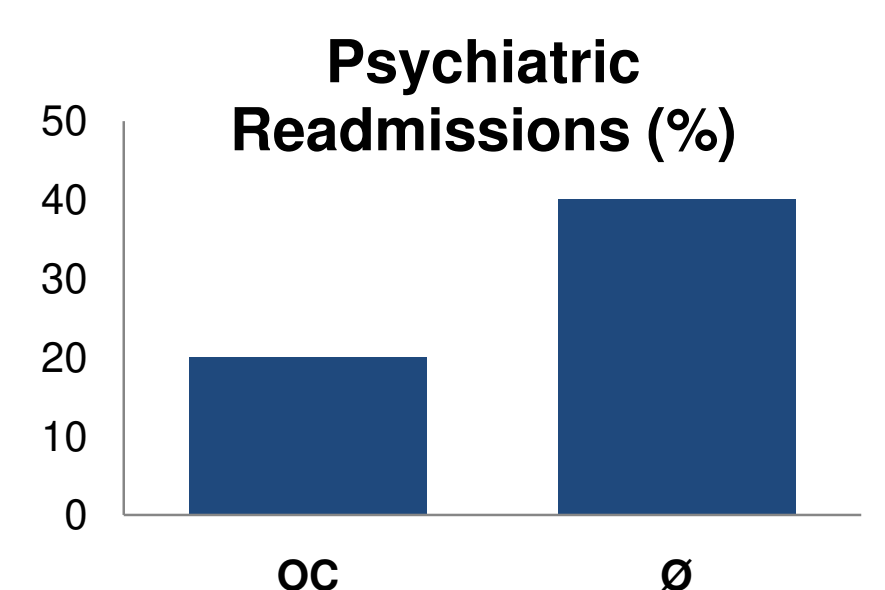

Suicide attempts

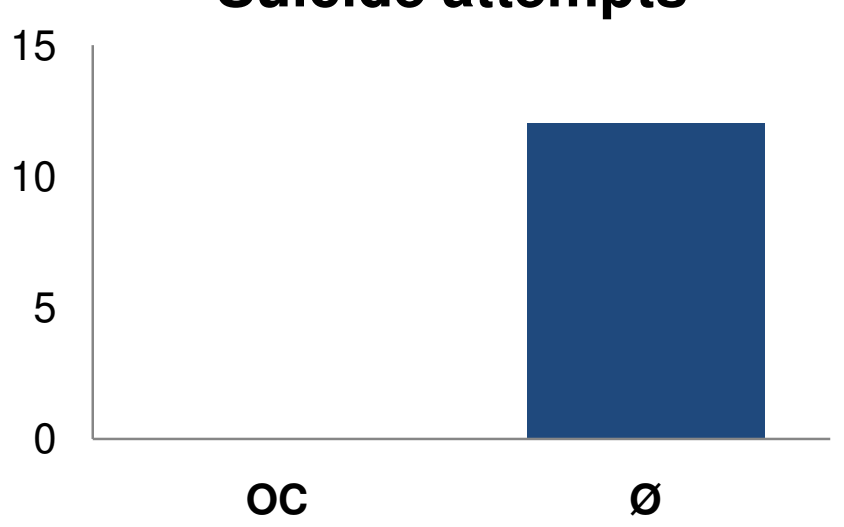

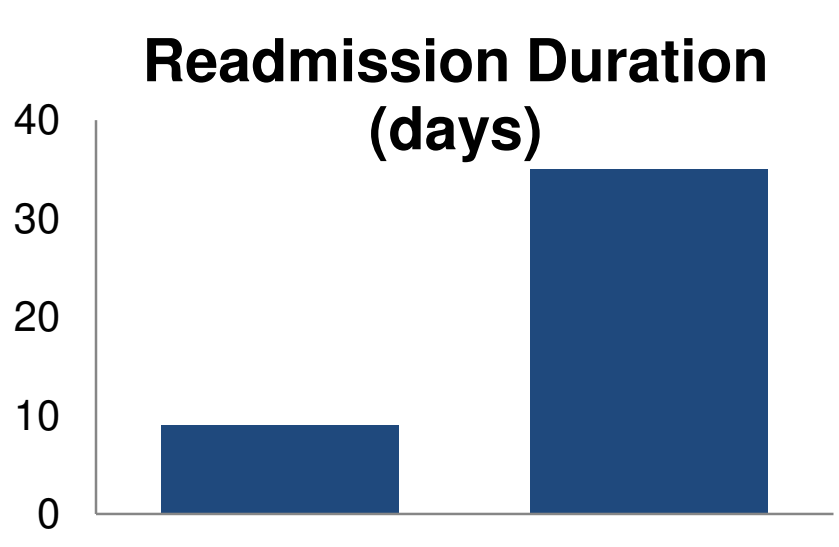

OC

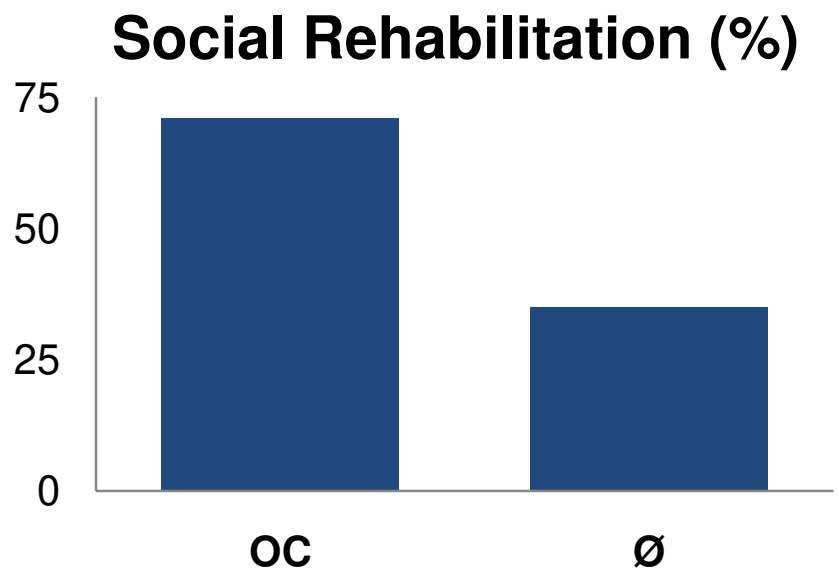

OC

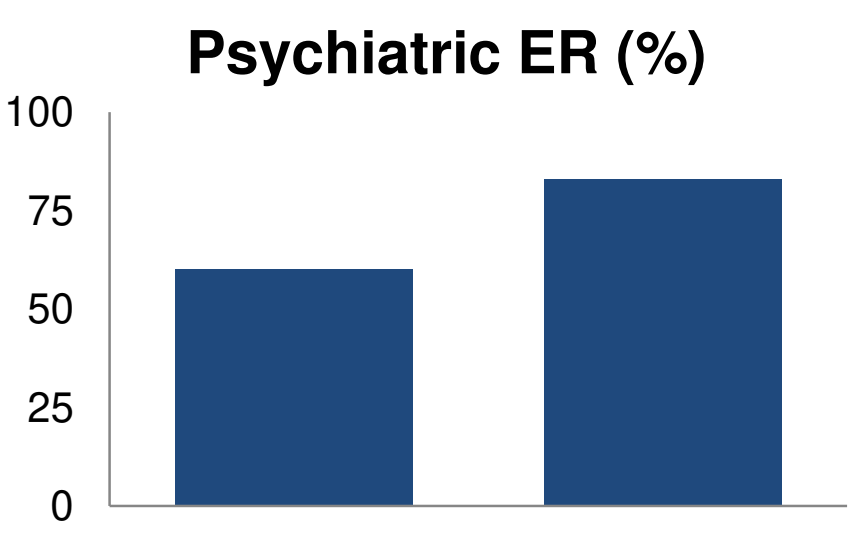

oc

$\varnothing$

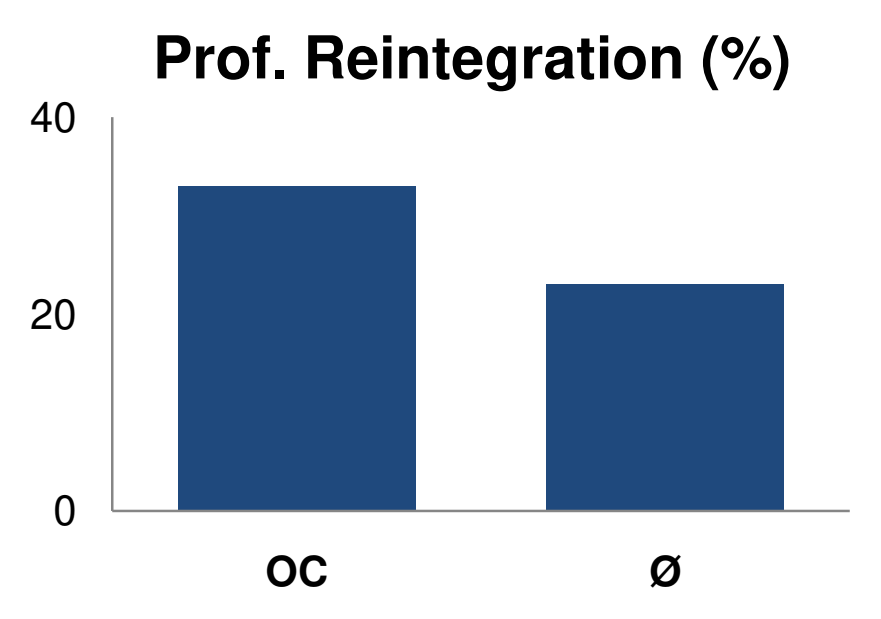

CONCLUSIONS:

This study shows that Psychiatric OC attendance in MDD inpatients after discharge is a valuable rehabilitation tool, contributing to clinical gains, such as fewer psychiatric readmissions, shorter readmission duration, lower Psychiatric ER attendance, fewer suicide attempts and favoring social rehabilitation and professional reintegration. 